\title{
SUSTENTABILIDADE URBANA E AS CERTIFICAÇÕES AMBIENTAIS NA CONSTRUÇÃO CIVIL
}

\section{Urban Sustainability and Environmental Certifications in Construction}

Paulo Cesar Zangalli Jr Mestrando em Geografia, FCT/UNESP, Presidente Prudente. Bolsista FAPESP pauloczangalli@gmail.com

Artigo recebido em 22/10/2012 e aceito para publicação em 11/12/2012

Resumo:

Abstract:

\begin{abstract}
Ainda é grande o debate que envolve as questões de sustentabilidade, sobretudo sustentabilidade urbana. Este artigo procura estabelecer uma crítica aos modelos de cidades sustentáveis e de cidade pós-moderna estruturada pelo modelo de cidade dispersa produzida pela lógica do capital, trata-se de um esforço teórico metodológico de confrontar dois modelos de cidades, o modelo capitalista de produção do espaço e o modelo sustentável de cidade, ou seja, o modelo de cidade dispersa contra um modelo de cidade compacta. Para isso foi utilizado como exemplo as certificações ambientais para a construção civil que denotam um rotulo de construção sustentável quando na verdade articulam uma série de simbolismos que mascaram e reafirmam os processos de produção da cidades na perspectiva do capital.
\end{abstract}

Palavras-chave: Sustentabilidade Urbana, Produção do Espaço, Simbolismo Ambiental, Cidade Dispersa, Certificações Ambientais.

There is a huge debate surrounding the sustainability issues, especially urban sustainability. This article seeks to establish a critique of models of sustainable cities and postmodern city structured by dispersed city model produced by the logic of capital, it is an effort to confront methodological theoretical models of two cities, the capitalist model of production space and model sustainable city, the dispersed city model against a model of the compact city. For example it was used as environmental certifications for building a label denoting sustainable building when actually articulate a series of symbols that mask and reaffirm their production processes from the perspective of capital cities

Key-words: Urban Sustainability, Production of Space, Environmental Symbolism, Dispersed City, Environmental Certifications. 


\section{INTRODUÇÃO}

Um dos desafios deste século, sem dúvida, é superar o conflito entre desenvolvimento e preservação do meio ambiente. Para muitos pesquisadores estes são dois caminhos que em momento algum se cruzam, no entanto, para outros esta dialética pode ser amparada pelo desenvolvimento sustentável, desde que realmente haja esforços mútuos entre os agentes econômicos, ou entre Estado e agentes econômicos. No entanto, esta é uma discussão que vai permear o meio científico e econômico por muito tempo e que demonstra que de fato está longe de esgotar o processo de consolidação dos conceitos.

Até pouco tempo atrás o debate não se materializava no espaço (a não ser em ações pontuais de preservação), mas agora parece que a cidade tem se tornado palco da materialização do debate ambiental, talvez por ser o local onde se concentram a maior parte da população mundial e consequentemente a maior parte dos problemas ambientais do planeta. Essa materialização ainda pode ser explicada pelo fato da indubitável incapacidade de antecipação frente aos problemas globais que tem sua origem nos modelos de organização e gestão da realidade local.

Mas, se a discussão se materializa no plano da cidade, no discurso dos projetos urbanos essas práticas ambientais estão longe de se concretizar e, quando é levada em consideração se estabelece no provimento de áreas verdes e de revitalização de parques urbanos, ou ainda na obtenção de certificações ambientais. No entanto, essas certificações ambientais, ou sustentáveis, que geralmente são adquiridas por empreendimentos imobiliários na verdade possui o intuito, muitas vezes de atrair investimentos com a tentativa de inserção no modelo de competitividade global, buscando se tornar cidades modelares ao invés de preservar o meio ambiente, ou adequar o ambiente urbano à um projeto de cidade sustentável.

A discussão que transpassa e se insere no âmbito da sustentabilidade urbana, muitas vezes, vem amparada pelo modelo de cidade compacta, de usos mistos, onde quase tudo que a cidade consome estaria sendo produzindo ao seu entorno, um modelo de cidade local e não global. Mas, ao contrário disso, a produção do espaço segue a lógica capitalista, ampara- -se na especulação imobiliária e na maximização dos lucros, provocando profundas mudanças nas estruturas territoriais urbanas criando um processo de periurbanização ou difusão reticular, muitas vezes, negando o próprio núcleo urbano polarizador e o resultado de todo esse processo é o que Dematteis (1998) vai chamar de cidade difusa.

Diante disso, surge a necessidade de se debater os dois modelos de cidades o de cidade compacta amparada pela produção sustentável do espaço urbano - e o modelo de cidade dispersa - fundamentada principalmente no modo de produção capitalista do espaço. Isso se faz para refletir se há a possibilidade de, em algum momento, se consolidar um modelo de cidade sustentável ou se as práticas que embasam esse modelo não atuam simplesmente como instrumento de atração econômica para, de certo modo, legitimar um discurso hegemônico, o do próprio capital.

Este processo dialético entre o modelo de cidade difusa, e o processo de implantação de políticas sustentáveis na cidade constrói um paradigma intrigante, é possível falar em sustentabilidade urbana? E de que forma os paradigmas da mesma passarão a integrar (se passarão) a agenda das políticas urbanas? De fato, o modelo de cidade que estamos produzindo esta longe de ser algo ideal.

As certificações ambientais aparecem nesse contexto como uma alternativa estratégica para produzir o espaço de forma mais sustentável, atendendo a uma série de exigências que torna um empreendimento mais atraente e eficaz para o desenvolvimento do plano da cidade. Mas será mesmo que essas exigências possuem capacidade para transformar a cidade num espaço mais igual e menos agressivo ao meio ambiente? Será que essas especificações técnicas contidas nas avaliações impostas pelas certificadoras não atuam como mero fator de atração de investimentos, atendendo a novas exigências do capital?

Diante de indagações como essas surgem questões relativizadas, ou seja, questões que de certa forma emperram o processo de consolidação dos conceitos e do desenvolvimento eficaz da produção de um espaço urbano mais igualitário. Assim, a apropriação dessas questões ultrapassa a esfera do real e vem carregada de um simbolismo transformando a discussão em mero instrumento de adequação ao 
mercado, ou em estratégias de marketing por parte dos agentes especuladores.

Nesta perspectiva, faz-se extremamente necessário contrapor o modelo de cidade produzido pela lógica capitalista e o modelo de cidade proposto pela agenda ambiental/sustentável para que possa avançar na discussão de que modelo de cidade queremos produzir daqui em diante. Pra isso usaremos diferentes tipos de certificações ambientais utilizadas como estratégia - ou que deveria ser usadas como - para prover o desenvolvimento sustentável do ambiente urbano, mas que muitas vezes atendem ao propósito da especulação imobiliária que produz o espaço conforme rege o capital sendo apropriados pelo marketing ambiental, agregando uma série de simbolismos para mascarar os reais danos ambientais e sociais causados por estes empreendimentos ao longo do seu processo de construção. Deve ficar claro, porém, que as certificações ambientais para a construção civil vão servir, nesse trabalho, como instrumento para exemplificar as conclusões advindas do debate entre os diferentes modelos de produção do espaço urbano.

\section{SUSTENTABILIDADE URBANA, O PILAR QUE EQUILIBRA O PRÉDIO}

A noção de sustentabilidade está longe de se tornar um conceito, sendo considerado como um "conceito infinito" com várias definições e uma gama de possibilidades que a maioria ainda não conseguiu compreender (ACSELRAD, 2001). Por este motivo aparecem, também, princípios que norteiam a construção do conceito e procuram estabelecer suas crenças e sua hegemonia discursiva. Em todas as tentativas de construção do conceito, o centro da ideia é circundado por construções de modelos econômicos, o que leva à reflexão de que toda a noção de sustentabilidade não vem amparar a preservação do meio ambiente, mas sim a preservação e a alocação de recursos que permitam o pleno desenvolvimento econômico daqueles que prosperam e lucram com o atual modelo econômico.

Tanto é que, a proposição central do discurso da sustentabilidade é fundamentada na eficiência no uso dos recursos do planeta. Essa eficiência poderia ser alcançada através da alocação eficiente dos recursos, ou seja, aquela capaz de respeitar as preferências dos consumidores ponderadas pela capacidade individual de pagamento, mantendo-se inserida num modelo de mercado competitivo onde vigorariam preços relativos determinados pela oferta e pela demanda (ACSELRAD, 2001). A auto- regulação do mercado induziria à produção de novas tecnologias limpas, e as falhas geradas pelo livre comercio que geram a degradação ambiental, seriam supridas pelo pagamento de taxas pigouvianas ou com reformas dos sistemas fiscais (taxar mais o uso dos recursos e a produção dos rejeitos), como bem elucida a economia ambiental neoclássica.

Na busca pelo espaço de construção do conceito, ainda, aparece a necessidade de emergir um mundo mais justo, partindo do principio da inseparabilidade analítica entre justiça e ecologia. O fundamento desta vertente é dado sobre os preceitos de que sem justiça e co-participação na prosperidade, não se conseguirá envolver os países pobres na gestão comum do meio ambiente global. Por ultimo, vale ressaltar a vertente da auto-suficiência que se dirige contra os propósitos do livre comércio, afirmando que a crescente globalização da economia aumenta as desigualdade e por conseqüência a degradação ambiental, propondo um modelo de produção local, com relações tradicionais com o meio físico natural.

É a partir destes discursos que vai ser fundamentada a associação da sustentabilidade com a produção da cidade. Se a cidade é palco de intensas disputas e interesses que definem os rumos da produção do espaço urbano, quase sempre atendendo interesses da elite local, a associação da noção de sustentabilidade com o debate do desenvolvimento das cidades não seria diferente, como mostra Acselrad (2001):

A associação da noção de sustentabilidade
com o debate sobre desenvolvimento das ci-
dades tem origem nas rearticulações políticas
pelas quais um certo numero de atores envol-
vidos na produção do espaço urbano procu-
ram dar legitimidade às suas perspectivas,
evidenciando a compatibilidade das mesmas
com os propósitos de dar durabilidade ao
desenvolvimento, em acordo com os princípios
da agenda 21 .

Todos estes interesses estariam associados à inserção da cidade no modelo de competitividade glo- 
bal, como estratégia de implementação da metáfora de cidade-empresa. $\mathrm{O}$ estabelecimento e o cumprimento de normativas ambientais proporcionam às cidades supostos atributos que no contexto da competição global vai the aferir maiores investimentos. Brand (1999) afirma que "é possível arguir que o ambientalismo urbano procura tornar a natureza transparente e visível, numa resposta exorcizante dos medos não só da destruição ecológica, mas também de uma ordem social instável".

Certamente a noção de sustentabilidade ultrapassa a perspectiva do natural e busca articular a relação entre sociedade e natureza. Sem considerar esta relação certamente na há como debater princípios ambientais, até porque toda concepção que cerca a noção é socialmente construída, seja ela no âmbito global ou inserida no ambiente urbano. Para Swyngedouw, o próprio ambiente urbano é uma mistura de social e natural mutuamente integrada.

Observando mais de perto, a cidade e o processo urbano são uma rede de processos entrelaçados a um só tempo humanos e naturais, reais e ficcionais, mecânicos e orgânicos. Não há nada puramente social ou natural na cidade, e ainda menos anti-social ou antinatural; a cidade é ao mesmo tempo natural e social, real e fictícia. Na cidade, sociedade e natureza, representação e ser são inseparáveis, mutuamente integradas, infinitamente legadas e simultâneas; essa coisa hibrida socionatural chamada cidade é cheia de contradições, tensões e conflitos. Urbanidade e urbanização capturam aqueles objetos em proliferação que Donna Haraway (Haraway, 1991) chama "cyborgs" ou a que Bruno Latour se refere como "quase objetos" (Latour, 1993); são eles intermediários que corporificam e mediam natureza e sociedade e tecem uma rede de transgressões infinitas e espaços fronteiriços (Swyngedouw, 2001, p. 84).

O caminho para se construir a sustentabilidade urbana passa, necessariamente, por esta concepção de socionatureza, no debate mais contemporâneo encontraremos uma série de articulações lógicas entre a reprodução das estruturas urbanas e a perspectiva ambiental.

Em muitos casos o desafio de conceber as cidades sustentáveis necessariamente passa pela máxima de "satisfazer as necessidades de seus atuais cidadãos sem esgotar os recursos das futuras gerações", e isso atrelado ao discurso econômico certamente leva a maximização e gestão dos recursos, quase sempre encarando a elaboração de agendas técnicas de implantação de medidas.

Brand (1999), no entanto, contrario a isso, defende que a cidade sustentável não seja encarada como uma agenda técnica, mas sim como "um ideal: uma fixação de aspirações sociais e significados espaciais com a capacidade de reorientar o sentido do desenvolvimento urbano e legitimar as ações estatais em nome do bem coletivo". Para isso o autor defende que a sustentabilidade seja algo que ultrapasse o real e encontre dimensões simbólicas dentro da sociedade que a concebe. Esta visão é uma visão muito qualitativa e, portanto, não apresenta dimensões técnicas palpáveis, o que vai torná-la uma proposta ainda com alguns limites segundo os princípios do planejamento urbano, que ao privilegiar questões mais técnicas não partilha de aspirações um tanto quanto teórica.

Uma proposta de melhor abrangência vem de Emelianoff (1995), que, ao analisar a rede de articulação de algumas cidades européias, constata que as mesmas procuram três frentes, gerando três perfis de cidades: a cidade ecológica, patrimonial e participativa. Cabe destacar, no entanto, a cidade ecológica uma vez que esta representa com grande eficiência um dos modelos de cidades sustentáveis que se busca.

Para a autora, a construção da cidade ecossistêmica é do interesse das cidades industriais, que sofrem os efeitos da poluição. A palavra de ordem de sua ação é uma vida saudável: "Elas (as cidades) se engajam num trabalho sobre a corporalidade da cidade, suas matérias efluxos. (...) Elas compreendem o ambiente global num sentido planetário. Sua ecologia se quer científica". Essas cidades se mobilizam para a prevenção do efeito estufa, contra a redução da camada de ozô- 
nio, a favor da reciclagem de rejeitos, numa concepção metabólica de cidade. Entre as estratégias que desenvolvem, estão a exploração de energias renováveis; a limitação dos deslocamentos humanos pendulares através do planejamento de zonas com funções mistas, da taxação da energia, do reforço à pedestrianização, de programas cicloviários, da não subvenção ao automóvel, e do encorajamento do teletrabalho ou do ensino à distância; e a diminuição dos transportes de bens, o encorajamento a uma economia da proximidade, a racionalização dos transportes, e a oferta de empregos locais. (MAGALHÃES, 2006)

Acselrad (1999) traz a construção da sustentabilidade urbana sobre três pilares, sendo: a representação tecno-material da cidade, como espaço de qualidade de vida e a cidade como espaço de legitimação das políticas urbanas.

A cidade vista como representação tecno-material se fundamenta na perspectiva da racionalidade energética, sendo vista em sua continuidade material de estoques e fluxos, proporcionando redução do consumo de energia fóssil e explorando ao máximo os recursos locais, reduzindo com isso o volume de rejeitos. A distribuição espacial inadequada torna-se um mecanismo que impede os avanços sustentáveis. Como espaço de qualidade de vida - "Componentes não mercantis da existência cotidiana e cidadã da população urbana", ou seja, a cidade como um campo que favoreça o desenvolvimento do diálogo e da negociação no sentido de preservar o patrimônio social e natural, reforçando as identidades, os valores e as heranças construídas. Já o modelo de cidade como espaço da legitimação das políticas urbanas procura estabelecer um projeto urbano pautado na equidade e eficiência.

Dentro dessa discussão talvez a que mais compareça nas ações do planejamento urbano sejam aquelas estipuladas pela Agenda 21, um dos avanços mais importantes firmados na II Conferência das Nações Unidas sobre Meio Ambiente e desenvolvimento Humano (CNUMAD), também conhecida como ECO92, constituindo-se num programa de ações baseado em 40 documentos, na tentativa de estipular um novo padrão de desenvolvimento, buscando conciliar preservação do meio ambiente, justiça social e eficiência econômica. Este documento é o mais utilizado talvez por ser um documento que aborda questões tanto qualitativas quanto quantitativas. As ações norteadas pela Agenda 21 são de caráter local e qualitativo, talvez pelo documento tratar de questões generalizantes com aspectos globais, o que o torna muito mais uma carta de intenções do que um elemento concreto (MAGALHÃES, 2006).

Os discursos que fundamentam a construção de modelos sustentáveis são interessantes, mas de certa forma elucida um plano de cidade um tanto quanto utópico e, enquanto isso, estamos no meio de um conflito que, de um lado, busca renovar os princípios da economia neoclássica e, de outro, os princípios de fortalecimento do estado frente a regulamentação de ações locais. Enquanto no plano científico tenta-se firmar um conceito ideal de sustentabilidade, no plano econômico encontramos cada vez mais modelos competitivos de cidades globais, para atrair de acordo com ações de livre mercado, estipulada pela economia neoclássica ambiental, maior investimento e atratividade, o que nos remete a um patamar apenas de reformulação econômica e não de preservação ambiental.

\section{A PRODUÇÃO DO ESPAÇO URBANO}

Não é por acaso que as cidades concentram a maior parte da população mundial. Desde seu surgimento, datado por volta de 3500 a.C. na região da Mesopotâmia, a cidade desempenhou papéis de cunho social, político e econômico, situando-se às margens dos rios, o que propiciava o desenvolvimento da agricultura; porém estas cidades antigas, ou cidades pré-capitalistas eram essencialmente políticas (SPOSITO, 1988). Diferentemente, a cidade capitalista pode ser concebida como expressão da produção industrial e da reprodução da força de trabalho, deixando de ser essencialmente política e tornando-se palco de um desenvolvimento desigual alicerçado pela dicotomia capital e exploração do trabalho (mais-valia).

Segundo Correa (2000):

O espaço urbano capitalista-Fragmentado, articulado, reflexo, condicionante social, 
cheio de símbolos e campo de lutas - é um produto social, resultado de ações acumuladas através do tempo, e engendradas por agentes que produzem e consomem espaço (...) derivando da dinâmica de acumulação de capital, das necessidades mutáveis de reprodução das relações de produção, e dos conflitos de classe que dela emergem (...) inclui práticas que levam a um constante processo de reorganização espacial que se faz via incorporação de novas áreas ao espaço urbano, densificação do uso do solo, deterioração de certas áreas, renovação urbana, relocação diferenciada da infra-estrutura e mudança, coercitiva ou não, do conteúdo social e econômico de determinadas áreas da cidade.

O espaço urbano adquire cada vez mais importância para o capital, ao mesmo tempo em que é influenciado pela dinâmica do modo de produção capitalista. Isso ocorre no instante em que os processos passam a ser guiados pelos dizeres da propriedade privada, e são regulados pelas necessidades do capital de gerar excedente.

A lógica de produção do espaço urbano é determinada por um conjunto de agentes locais que controlavam os negócios imobiliários e imobilizavam o capital na consolidação da propriedade da terra e assim desempenhando importante papel no processo de geração e apropriação da riqueza social. Estes agentes ainda transformam a lógica de produção do espaço intraurbano regidos pela lógica da valorização fundiária, de uma seletividade e diferenciação de áreas (MELAZZO, 2010). Mas, cada vez mais as ações destes agentes são minimizadas "ao papel de influenciar, com capacidade bastante reduzida, as formas espaciais que estão sendo conformadas, já que as escolhas relativas aos novos modos de vida, em novos habitats sejam eles urbanos ou não, estão sendo feitas em escalas mais amplas ou por elas influenciadas" (SPOSITO, 2009).

Para Abramo (1989), um dos principais produtores do espaço urbano é o capital incorporador; "é ele que efetua a transação de compra e venda de terreno, define seu uso futuro, encomenda os projetos e estudos arquitetônicos e de engenharia, contrata os capitais construtores, define as estratégias de venda e viabiliza o financiamento". No Brasil, o capital incorporador se constituía num capital rentista: mas, no atual momento econômico essa perspectiva rentista, ainda que persista, tem sido incorporada pelo capital financeiro, articulando cada vez mais o mercado fundiário em um sistema de ações globais.

Essa inserção no sistema financeiro global denota ao capital uma liquidez que transforma o mercado imobiliário. A produção do espaço urbano para atender às necessidades do mercado financeiro aumentou de forma bastante considerável e cada vez mais, com empreendimentos que procuram atender a segmentos populacionais específicos, com padrão aquisitivo capaz de adquirir estes produtos comerciais. Para que o incorporador lançasse suas ações nas bolsas de valores, era necessária uma garantia, que veio com a incorporação de bancos de terras tornando-se proprietário da terra. Para Belleza apud Miele (2008), o terreno teria se transformado em ouro em pó, pois o aumento da produção imobiliária levaria a uma escassez de terrenos. Para Miele isso reflete muito mais nos empreendimentos comerciais, uma vez que estes dependem muito mais da conjuntura econômica. Já para os empreendimentos residenciais a dependência da localização não toma muita forma, podendo ser realizados em vários lugares, o que nos apresenta um primeiro elemento para compreensão de uma urbanização que cada vez mais se apresenta de forma fragmentada.

Ao atender os interesses do capital e ao reforçar as diferenciações sócio espaciais com empreendimentos cada vez mais voltados a segmentos sociais específicos, vamos nos deparar frente às urbanizações cada vez mais dispersas ou como identifica Dematteis (1998) como um processo de periurbanização e difusão reticular (cidade difusa). Segundo o autor a combinação de duas dinâmicas é que vai gerar estes tipos morfológicos. A primeira vai emergir na recuperação da polarização urbana que se manifesta pela expansão progressiva das periferias e nas ramificações radiais dos sistemas urbanos com uma redução de moradores nos núcleos centrais das cidades. A segunda dinâmica se manifesta nas formas de expansão urbana independentes dos campos de polarização dos grandes centros urbanos. Periurbanização pode ser interpretada como 
uma situação de desenvolvimento mais débil, no qual o desenvolvimento depende apenas das funções de serviços (e eventualmente industrial) de um pólo urbano dentro de um contexto regional. A difusão reticular (cidade difusa) é uma característica de tecidos mistos, tanto residenciais quanto produtivos, derivados seja de dinâmicas endógenas, seja pela descentralização metropolitana de amplo raio.

Nesse processo difuso, a concepção de cidade dispersa torna-se parte da conformação de uma urbanização difusa, dada pela intensificação da circulação, propiciada pela ampliação das formas de se deslocar e se comunicar. Sendo assim, na cidade dispersa é de fácil percepção a conformação de novos tipos de periferias urbanas, que para compreendermos devemos "reconhecer sua diferença a respeito das periferias urbanas da fase precedente, diferença que não se apresenta somente na forma (...), mas também na modalidade de organização territorial, de composições sociais e de desenvolvimento" (DEMATTEIS, 1998). As novas periferias se dissolvem pelo território do campo deixando cada vez menos perceptível os limites entre rural e urbano e intensificando o conflito conceitual cidade/campo, deixando essa diferenciação mais a cargo dos usos e funções do que para os limites propriamente ditos.

Essa dissolução é uma tendência de produção do espaço urbano, a partir de lógicas de expansão territorial marcadas pela descontinuidade em relação às áreas implantadas e ocupadas anteriormente, conformando cidades dispersas (MONCLÚS, 1999) responde, com grande intensidade, no caso brasileiro, aos interesses dos agentes da produção do espaço urbano. O aumento da oferta de novos lotes urbanos, cada vez mais distantes, reflete o ritmo mais acelerado com que essa produção de novos espaços realiza-se comparativamente à evolução do crescimento demográfico (SPOSITO, 2009).

Essa dispersão deixa no espaço uma série de fragmentos do urbano, que apresentam elementos indutores dessa urbanização para fora dos aglomerados tradicionais, com centros hegemônicos bem definidos, nos revelando um processo que pode ser chamado de contra-urbanização (DOMINGUES, 1999).

Assim, a cidade é pensada e vivida aos pedaços, de modo sempre provisório ou por tempos curtos, pois não há mais âncoras sociais, políticas ou econômicas que nos atrelem a ambientes urbanos elou nos façam apreender a cidade como um conjunto (SPOSITO, 2009).

À medida que se aprofunda na urbanização difusa e em todas as vertentes que deriva desta, os antigos lugares centrais fortemente marcados por um processo de hierarquia urbana começam a se dissolver na mancha urbanizada, as áreas de influências sobrepõem-se, surgem novas áreas de influência, novas centralidades fora dos aglomerados tradicionais. Mas, concomitante a este processo, ao mesmo tempo em que se desfaz uma hierarquia urbana tradicional reconstitui-se novos centros de poder hegemônico, alicerçado em novas atividades econômicas e estruturais.

A articulação das cidades passa a ser desenhada por um emaranhado de redes urbanas cada vez mais complexas que inserem algumas cidades inclusive em circuitos globais de produção e informação, o que dificulta a implementação de práticas que possam ir ao encontro de soluções possíveis para a minimização dos efeitos causados pela cidade dispersa, uma vez que em um mundo cada vez mais globalizado há uma dissolução entre poder e ações políticas, sendo que o poder fica atrelado a questões globais e as ações políticas não alcançam dimensões planetárias. Isso nos leva a pensar que a consolidação de modelos que queiram ser implantados esbarra muitas vezes nas decisões do poder econômico (SPOSITO, 2009).

As práticas que norteiam a expansão e retratam essa fragmentação, reafirma a ideia de que a cidade não pode ser vista mais como um espaço de unidade urbana. O processo de produção do espaço, sobretudo o espaço urbano, segue uma lógica objetiva e subjetivamente à lógica do capital, mas ao mesmo tempo simbólica, produzindo uma série de elementos que acompanham e reforçam os princípios implantados por uma sociedade do consumo neoliberal.

A imposição de simbolismos como o do aumento da insegurança, o do consumo sustentável 
constroem um processo onde não existe sujeito. A sociedade não atua como produtora do espaço urbano, mas como um mero espectador retratado na forma de consumidor, mas também de mercadoria.

A partir disso, reestrutura-se e desestrutura-se a forma urbana, pois ao mesmo tempo em que novas práticas - regulamentadas pela ação de mercado - emergem para formação de novas estruturas urbanas, velhas práticas são reafirmadas. No modelo capitalista o excedente é fundamental na composição do lucro e o excedente de mão-de-obra é fundamental para a manutenção dos sistemas, assim como afirma Kowarick (2009) ao dizer que a construção de uma sociedade vulnerável "neste sentido, tem sim uma finalidade, qual seja, a de reproduzir a ordem social que é sua desgraça". Essa construção social, espacial e de mercado vem para justificar empreendimentos que cada vez mais negam a cidade, minimizando a importância do espaço público restringindo-os ao uso de espaços coletivos, onde o direito de ir e vir e a expressão das diferenças são restringidos, justificando a necessidade de isolamento.

Todo esse processo flexível culmina no que SPOSITO (2009) vai chamar de "expressão espacial da individualização da sociedade", a circulação seja ela de pessoas, bens ou fluxos imateriais acaba tomando mais importância que a localização. Cada vez mais os processos culminam em negar a cidade como um meio de unidade social. Assim,nos deparamos com a conformação de espaços dispersos que reafirmam as desigualdades e novamente buscam consolidar espacialmente o processo de produção atual, regido pela acumulação flexível do capital.

\section{CERTIFICAÇÕES AMBIENTAIS?}

Até este momento apresentamos dois debates, um que gira ao redor das questões da sustentabilidade e mais precisamente dos modelos de sustentabilidade urbana, o outro faz referência ao modelo de cidade dispersa, de uma urbanização difusa orientada pela lógica do capital que num período pós-moderno se caracteriza pela financeirização e liquidez de mercado. É notório que por mais que se procurem modelos, é muito difícil a articulação da produção do espaço ur- bano capitalista com modelos de cidades sustentáveis. Para muitos autores, desenvolvimento econômico e preservação ambiental não dialogam no mesmo dialeto, isso porque a sustentabilidade procura estabelecer o conflito entre o modelo de cidade que vem sendo produzido e um modelo de cidade compacta ou eficientemente local.

Reduzo-me a pensar que não são as cidades ou a urbanização que a sustentabilidade urbana busca preservar e sim a satisfação de necessidades humanas em assentamentos de qualquer tamanho, sem o esgotamento do capital ambiental, ou dos recursos necessários para manutenção da mesma. Seria então uma forma de preservação do meio ambiente, ou uma adequação do modelo econômico ao risco do esgotamento dos recursos?

Se no plano conceitual a sustentabilidade encontra uma série de possibilidades, na pratica encontramos uma busca cada vez maior por atratividade e investimentos, ou seja, medidas pontuais que procuram atender a interesses do capital. Foi o que inseriu no plano do planejamento urbano de algumas cidades a emergência de medidas sustentáveis, e o que fundamenta o numero cada vez maior de empreendimentos que procuram por certificações ambientais.

Essas certificações são normativas que estabelecem um padrão de planejamento, construção, gestão e comercialização de empreendimentos. A Certificação, portanto, consiste na declaração, efetuada por um organismo de certificação, de que um produto, processo ou sistema está conforme a requisitos especificados. Mas que requisitos? E que organismos?

Existem muitas empresas privadas que estabelecem certificações ambientais sustentáveis. Um ponto interessante é que não há entre elas um padrão técnico de sustentabilidade, sendo que cada uma adota a que melhor couber dentro de suas especificações. Neste artigo vamos utilizar como exemplo as certificações Leed (United States Green Building Council) e o processo Aqua (Démarche HQE), pois são as que mais crescem no mercado de certificações brasileiro. A figura a seguir mostra como funcionam os padrões técnicos de normatização de cada certificadora, valendo a ressalva de que não há um diálogo conceitual sobre o que seria sustentabilidade urbana entre as empresas.

A Revista Construção mostrou que no ano de 
2011 dobrou o numero de procura por tais certificações, sendo que até setembro do mesmo ano o processo Aqua já havia certificado 42 edificios (aumento de
$100 \%$ com relação ao mesmo período do ano anterior) e o processo Leed 16 empreendimentos, mas já haviam outros 197 pedidos e certificação.

Figura 1: Certificadoras Ambientais

\begin{tabular}{|c|c|c|c|}
\hline 0 que è & Como funciona & Categorias de análise & $\begin{array}{l}\text { Como participar } \\
\text { e quanto custa }\end{array}$ \\
\hline $\begin{array}{l}\text { Leadership in Energy and } \\
\text { Erwironmental Design ê um } \\
\text { sistema americano de } \\
\text { certificaçz̄o aplicado pelo } \\
\text { USGBC (United States } \\
\text { Green Building Council) que } \\
\text { leva em conta o impacto } \\
\text { gerado ao meio ambiente } \\
\text { em consequência dos } \\
\text { processos relacionados ao } \\
\text { edificio (projeto, construçāo } \\
\text { e operação). }\end{array}$ & $\begin{array}{l}\text { Pontua soluçōes nos } \\
\text { quesitos: espaço } \\
\text { susten tável, localização, } \\
\text { entorno, eficiência no uso } \\
\text { de água e de energia, } \\
\text { qualidade do ar, uso de } \\
\text { materiais, qualidade } \\
\text { ambien tal interna, } \\
\text { inovação e processos. Usa } \\
\text { um cheklist com as } \\
\text { principais exigências das } \\
\text { sete categorias.A } \\
\text { pontuaçăo tem } \\
\text { classificação em Platinum } \\
\text { (platina), Gold (ouro) ou } \\
\text { Silver (prata). }\end{array}$ & 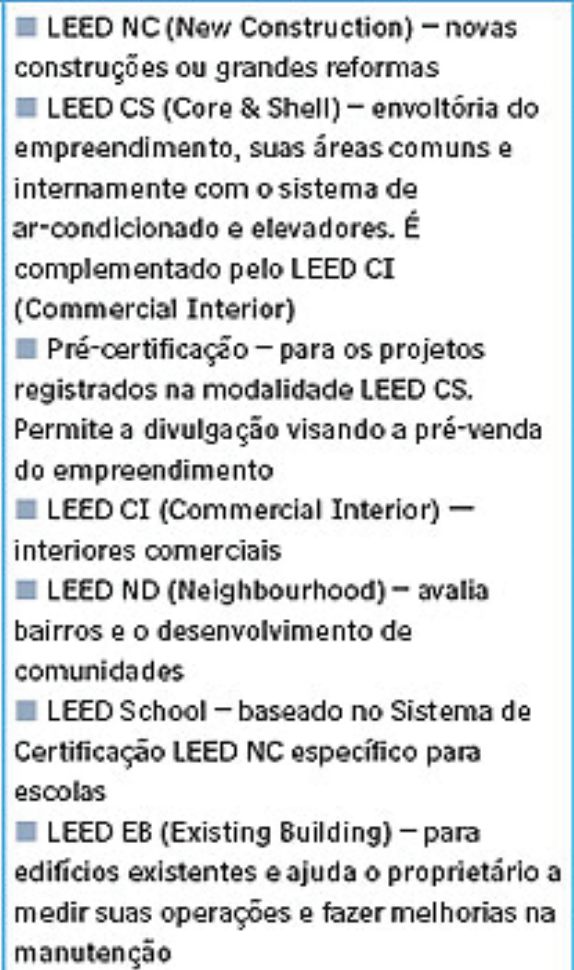 & 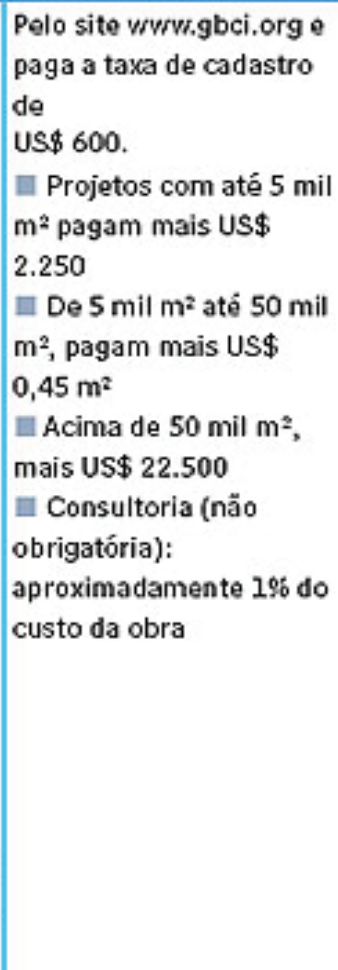 \\
\hline $\begin{array}{l}\text { AQUA } \\
\text { Processo AQUA } \\
\text { A certificação } \\
\text { Aqua (Alta Qualidade } \\
\text { Ambiental) é um processo de } \\
\text { gestäo de projeto implantado } \\
\text { pela FundaçäoVanzolini com } \\
\text { o objetivo de obter a } \\
\text { qualidade ambiental de um } \\
\text { empreendimento de } \\
\text { construçäo ou de reabilitação. } \\
\text { É baseado na certificação } \\
\text { francess Démarche HQE. }\end{array}$ & $\begin{array}{l}\text { Avalia: Programa (definiçāo } \\
\text { das necessidades eo } \\
\text { desempenho do projeto); } \\
\text { Concepção (o sistema de } \\
\text { gestāo propcsto é mantido } \\
\text { e há correçāo de eventuais } \\
\text { desvios); Realização (a } \\
\text { meta é alcançar o máximo } \\
\text { de eficiêndia com a menor } \\
\text { presença de desvios) e } \\
\text { Operação (obra até sua } \\
\text { conclusão). Em cada uma } \\
\text { das etapas, o } \\
\text { empreendimento passa por } \\
\text { auditorias e recebe uma } \\
\text { certíficação daquela fase. }\end{array}$ & $\begin{array}{l}\text { Todo o processo conta com } 14 \text { categorias } \\
\text { ou objetivos distribuidos em quatro bases } \\
\text { de ação: ecoconstruçāo, ecogestão, } \\
\text { conforto e saúde. O empreendedor é } \\
\text { pontuado por três níveis de desempenho: } \\
\text { excelente, superior e bom. Para obter a } \\
\text { certificação deve alcançar pelo menos três } \\
\text { niveis "excelente" e quatro "superior". }\end{array}$ & 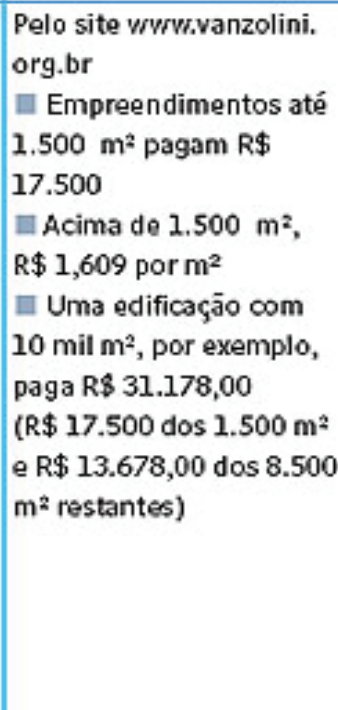 \\
\hline
\end{tabular}

Fonte: Revista Techne, n. 155, 2011. 
O que acaba acontecendo na definição dos processos é que são elaborados uma série de mecanismos, que por sua vez são organizados em uma forma de checklist que se tornam padrões do que seria sustentável. Muito nos parece que este checklist não procura estabelecer um padrão que articula o desenvolvimento social e ambiental, pelo contrário, procura estabelecer um padrão muitas vezes internacional de eficiência que certamente vai ser atrativo de investimentos futuros, além de que essa eficiência diminui os custos de gestão e manutenção do empreendimento, possibilitando a maximização dos lucros. A maior parte dos empreendimentos certificados pela Green Building Council (Leed) no Brasil é de edifícios comerciais.

Vamos utilizar o exemplo de certificação Leed CS - Gold (Core and Shell Development Project) do empreendimento comercial Rochaverá Corporate Towers na cidade de São Paulo, onde segundo a certificadora o empreendimento conseguiu aliar o máximo de aproveitamento dos recursos naturais com a redução do impacto ambiental da construção, durante a obra e, também, no período de funcionamento do edifício. São apontadas medidas como elevadores com sistema de antecipação de chamada e regenerador de energia para reduzir o consumo. $\mathrm{O}$ ar-condicionado também utiliza um sistema descentralizado, que possibilita seu desligamento quando não há usuários em um determinado ambiente. Mas, se a sustentabilidade busca articular o desenvolvimento social e ambiental, onde é que estariam os ideais de equidade social? Ao invés disso todos estes elementos articulados procuram uma melhor gestão e maximização dos lucros reafirmando os processos de acumulação capitalista.

Certamente a procura pelos "selos verdes" não emerge da preocupação com o meio ambiente, ou com os ideais de equidade social, mas sim na articulação simbólica criada pelos ideais de consumo. Na produção do espaço, indissociavelmente, são produzidos um conjunto material e um conjunto simbólico, ora para valorizar, ora para desvalorizar os empreendimentos. Dessa forma, quando analisamos a produção do espaço necessariamente necessita-se a análise do conjunto simbólico que se materializa junto com cada empreendimento (OLIVEIRA, 2009).

No âmbito da sociedade de consumo, a funcionalidade dos objetos passa a ser algo secundário, tomando maior importância o conjunto de construções simbólicas que estão agregadas ao objeto, ou ao empreendimento. Quem vai ditar as regras desse jogo é o marketing produzido para reafirmar a necessidade simbólica do consumidor, para dizer que ele necessita daquele conjunto de símbolos. O marketing não vai mostrar o conjunto técnico de produção que alicerçou todo o processo de construção e certificação, mas vai sugerir que ao consumir voce adquira um conjunto simbólico, que para os empreendimentos certificados, vem propor um novo padrão de consumo: o consumo "consciente".

As escolhas locacionais feitas para constituição de empreendimentos imobiliário de padrões como o apresentado implicam também na lógica de expansão do tecido urbano, quando realizados de modo disperso, ou podendo ainda mudar todo o padrão do bairro em que se instalou, na maioria das vezes valorizando a área e consequentemente elitizando o padrão do entorno.

As práticas adotadas seja pelo planejamento urbano, seja pelos empreendimentos que buscam agregar um conjunto simbólico ambiental não vão ao encontro da articulação da sociedade natureza, na busca de uma justiça social e preservação ambiental; pelo contrário, essas ações, resumem-se em uma inserção num mercado de competitividade global para atração de novos investimentos. O capital produz o espaço, sobretudo o espaço urbano, gerando na maioria das vezes espaços desiguais e dialéticos. Pensar o meio ambiente, nesses espaços construídos, é pensar também na sustentabilidade, definida pelas próprias práticas do capital, alicerçando um discurso dialético e insuperável.

Se no desenvolvimento urbano capitalista a cidade foi produto e produtor do sistema, consolidando-se em bases de acumulação e reprodução do capital, se na cidade fordista a cidade consolidou-se conforme $o$ modelo de produção capitalista fordista orientava, e se no atual processo de acumulação flexível de liquidez de mercado a cidade se configura e reestrutura de forma dispersa e flexível, a emergência de um simbolismo ambiental começa a produzir cidade de acordo com a conformação de uma economia ambiental, seja ela qual for. A incorporação de um protecionismo ambiental não vem proteger o meio ambiente, mas satisfazer 
as necessidades (produção/consumo) do presente e garantir as necessidades (produção/consumo) para as gerações futuras.

Se Marx afirmou que o fetiche da mercadoria mascarava as reais condições de produção contidas no produto, com o propósito de fortalecer o consumo, poder-se-ia pensar então que a adoção de algumas práticas ambientais pelas empresas consolidam um novo fetiche, dessa vez ambiental, para mascarar os reais impactos e reestruturar novas práticas de consumo sem que o consumidor sinta-se destruindo o meio em que vive?

\section{CONSIDERAÇÕES FINAIS}

O desenvolvimento sustentável e consequentemente a sustentabilidade urbana estão longe de serem conceitos findados, mas constituem um processo que por um lado busca a introdução de novos modelos de eficiência e rompimento com o atual sistema de produção e, por outro lado, procura se reforçar em meio à estruturação cada vez maior de uma economia ambiental neoclássica. Na prática, são velhos discursos econômicos e sociais incorporando novas faces frente a uma modernidade líquida.

Enquanto não se define um ideal de desenvolvimento social e ambiental comum, as cidades seguem sendo produzidas por agentes econômicos que procuram atender às necessidades do capital e do sistema capitalista de produção, revelando um modelo de cidade cada vez mais dispersa e menos integrada, cada vez mais individualizada e com menores possibilidades de se chegar a uma equidade urbana e social.

Enquanto o caminho mais justo não é apontado, seguimos enclausurados em nossos muros de salvação da violência, consumindo, cada vez mais, produtos "sustentáveis" para salvar o planeta da maldição criada por nós mesmos.

\section{REFERÊNCIAS}

AGENDA 21 DO EIXO ATLÂNTICO. A Sustentabilidade Urbana: As bases teóricas do modelo. Bragança: Conselho de Bragança, 2005.
ACSELRAD, H. "Sentidos da Sustentabilidade urbana". In: ACSELRAD, Henri (org.) A duração das cidades: sustentabilidade e risco nas politicas urbanas. Rio de Janeiro: DP\&A, 2001, pp. 27-56

ACSELRAD, H. Discursos da Sustentabilidade Urbana. Revista Brasileira de Estudos Urbanos e Regionais. N.1, 1999, p. 79-90.

BRAND, Peter C. The Environment and Postmodern Spatial Consciousness: A Sociology of Urban Environmental Agendas. Journal of Environmental Planning and Management, 42 (1), 1999, p. 631-648

CAMPOS, P. A. A dinâmica imobiliária: elementos para o entendimento da espacialidade urbana. $\mathrm{Ca}$ dernos IPPUR, Rio de Janeiro, vol. 3, $\mathrm{n}^{\circ}$ especial, 1989, p.47-70.

COELHO, L. Certificação Ambiental. Revista Techne, n. 155, 2011. Disponível em: $<$ http://www.revistatechne.com.br/engenharia-civil/155/artigo162886-2.asp>, acesso em 24/01/2012.

CORRÊA. R. L. O espaço urbano. São Paulo: Ática, 1989.

DEMATTEIS, G. Suburbanización y periurbanización. Ciudadades anglosajonas y ciudades latinas. In: MONCLÚS, F. J. (ed.), La ciudad dispersa. Barcelona: Centre de Cultura Contemporânea de Barcelona, 1998.

DOMINGUES, A. Formas e escalas da urbanização difusa: interpretação e intervenção no No de Portugal. Revista Infogeo. Lisboa, n.14, Edições Colibri, 1999, p. 43-64.

MIELE, F. A. F. O movimento da economia financeira na dinâmica imobiliária de São Paulo. Dissertação (mestrado) em Geografia Humana. FFLCH: USP, São Paulo, 2008.

EMELIANOFF, Cyria. “Les Villes Durables: L'émergence de nouvelles temporalités dans de vieux espaces 
urbains". Ecologie Politique, n 13 , printemps 1995, pp. 37-58.

KOWARICK, L. Viver em risco: sobre a vulnerabilidade econômica e civil. São Paulo: Editora 34, 2009.

MAGALHÃES, R. A. M. A construção da Sustentabilidade Urbana: Obstáculos e Perspectivas. In: III ENCONTRO DA ANPPAS, Brasília, 2006. Anais..., Brasília, 2006.

REVISTACONTRUÇÃO MERCADO. Certificações Ambientais dobram em 2011. Disponível em: $<\mathrm{http}$ :/ www.revistatechne.com.br/engenharia-civil/155/artigo162886-2.asp>, acesso em: 23/01/2012.

SPOSITO, M. E. B. Urbanização difusa e cidades dispersas: perspectivas espaço-temporais contemporâneas. In: REIS, Nestor Goulart (Org.). Sobre a dispersão urbana. São Paulo: Via das Artes/FAUUSP, 2009. p. 38-54.

SWYNGEDOUW, E. A cidade como um híbrido: natureza, sociedade e "urbanização-cyborg". In: ACSELRAD, Henri. (org) A duração das cidades. Rio de Janeiro: D,P.\& A, 2001.

\section{AGRADECIMENTOS}

O trabalho foi realizado com auxílio financeiro da Fundação de Amparo à Pesquisa do Estado de São Paulo - FAPESP 